\title{
Analysis of the causes of College Students' employment psychological problems
}

\author{
Xin-Hua YAO and Yun-Heng ZHENG * \\ Beihua University ,Jilin, China \\ *Corresponding author: Yun-Heng ZHENG
}

Keywords: College students, Employment psychology, Causes.

\begin{abstract}
The employment psychological problems of contemporary college students has become one of the issues of great concern in the community. With the domestic and international economic scale and industrial structure adjustment, and economic slowdown, weakening the pulling effect on the employment of college graduates, the structural contradiction of supply and demand of the outstanding students increasingly serious employment situation. Therefore, the study of the causes of contemporary college students' employment psychology, the analysis of the factors affecting the employment of college students, and actively cultivate the employability of college students, is an important measure to ease the employment difficulties of College students.
\end{abstract}

\section{The status quo of College Students' Employment}

College graduates continue to grow in recent years, as a percentage of GDP growth to count, the growth rate of graduates greatly exceeds the number of GDP growth and create jobs, coupled with the impact of social environment and personal choice, the current college students increasingly serious employment situation. The status quo is as follows:

A. The number of college students waiting for employment continues to rise. With the increasing number of graduates graduating from universities every year, the number of graduates has been accumulating, so the number of college students waiting for employment continues to rise.

B. The overall imbalance of employment structure in china. First, the imbalance in regional employment, relatively speaking, the eastern coastal economy developed, relatively more employment opportunities, while the jobs are relatively small; second is the employment difference of different subjects and majors of the great.

C. College students are relatively passive in the job market. Most college students hesitate or make hasty decisions when choosing jobs because there is no clear career planning, which is also related to the strong position of the employment units.

\section{The realistic expression of College Students' employment psychological problems in the new period}

For college students, the lack of social experience, the lack of understanding of social needs, the gap between reality and ideal often lead to employment psychological pressure of College students. Through a comprehensive survey of college graduates, using the form of questionnaire to understand the psychological problems of college students when they are employed. The survey found that $99 \%$ of college students have a strong desire for employment, combined with their actual employment performance, better understanding of the employment of College students. Through the collation of data, summed up the psychological problems of college students employment mainly in the following aspects of performance.

A. Yangaoshoudi, quick psychology

With the development of employment environment and the change of employment mechanism, self employment is the main channel for college students' employment. But for some students, the 
influence of the traditional ideas, but in the employment, employment for paid jobs, work easily. For relatively ordinary posts, it is not consistent with the identity of College students. According to the survey, $57 \%$ of the college students in the employment of remuneration as the basis of choice, the use of wages to measure the amount of work. In this case, the majority of college students are easy to fall into psychological misunderstanding when they participate in employment, unwilling to engage in hard work, grass-roots work, and their own lack of management and ability, often produce psychological problems of quick success and instant benefit.

B. Inferiority, anxiety, lack of self-confidence

In the survey found that all belong to 90, with independence and dependence of coexistence of the times characteristics. They are paid too much attention to the group, as the only child growing up of a generation, from childhood has been given all aspects of attention, taken care of by parents. So they are accustomed to being accustomed to receiving care, thoughtfulness, lack of social experience and the actual contact, resulting in less social, afraid of contact with the interviewer in employment, the ability of their own lack of confidence. According to the survey, $61 \%$ of the students think that their own lack of experience in employment; $11 \%$ of the students in the interview nervous; 9\% students worried that she could not find a job, there is anxiety; only 19\% of students on employment is full of confidence. It can be seen that, in the employment of college students, most students prone to inferiority, anxiety psychological problems, so that students can not have a good understanding of their own ability, resulting in negative emotions breeding.

C. Lack of cognition, the psychology of blind job hunting

The diversified form of economic development, the new era of college students is faced with a variety of values, this thought is not mature for college graduates, more likely to cause confusion of values, for employment and career choices confused period. According to the survey, $42 \%$ of college graduates will choose a job as soon as they graduate so as to obtain psychological comfort. And the attitude is to try to choose a job; for job satisfaction, $84 \%$ of the students think it does not matter. This causes most students do not have a comprehensive understanding of their own ability and employment positions, there is a certain blind psychology. In the following work, it is easy to produce a variety of conflicts of interests, leading to the emergence of College Students' employment psychological problems.

D. Stable comparison, lack of active psychology

Facing the grim situation of employment of college students in the new era, for the pursuit of a secure job is favorable, and there are certain psychological comparisons, others think a better choice should be to the country, so the potential of their own are ignored, not for active. On the basis of not reaching the corresponding standard, some psychological problems are produced. According to the survey, $75 \%$ of students choose civil servants, institutions and state-owned enterprises in the employment tendency; $8 \%$ of the students choose their own businesses; $10 \%$ of the students choose the individual private enterprise; $7 \%$ of the students choose to employment grassroots difficult areas. This shows that most of the graduates do not have a correct understanding of their ability to actively create, can not adapt to challenging work, lack of active psychology.

\section{Analysis of the reasons affecting college students' Employment}

A. The structural imbalance between the supply of graduates and market demand is serious

Under the background of economic globalization, change by the overall international economic recovery is slow, the domestic economic structure and growth mode and unpredictable factors increase under the influence of other reasons, China's economic slowdown, reducing employment elasticity, economic development for college graduates to absorb the ability of relative reduction. But at the same time, the total supply of college graduates is increasing, a record high. For example, the number of college graduates in China increased from 1 million 450 thousand in 2002 to 4 million 130 thousand in 2006, from 6 million 300 thousand in 2010 to nearly 7 million 950 thousand in 2017. The structural contradiction between supply and demand of university graduates is prominent, which leads to structural unemployment of College students. 
B. The structural contradiction of College Students' training quality is outstanding

China's higher education has shifted from elite education to popular education. At present, has yet to establish a benign interaction mechanism and the demand of social and economic development of personnel training in Colleges and universities, the administrative color is still strong, education reform and structural adjustment is lagging behind, there are teachers, discipline structure and education training mode is not reasonable, specialty and curriculum content design system is not complete, professional recruitment and training of self restraint mechanism perfect, lack of market information, accurate prediction and scientific proof etc.. Many reasons lead to the contradiction between the quantity and structure of talent training and the demand of social and economic development.

C. The effectiveness of employment and entrepreneurship education is poor

Employment and entrepreneurship education in Colleges and universities is to cultivate students' professional awareness, professional ability and quality, entrepreneurial spirit and life planning ability based education, the purpose is to promote students' active employment and active entrepreneurship. Our government and education departments have attached great importance to the college students' employment problem, many universities have carried out the employment and entrepreneurship education and practice, has made some achievements, but the overall level of education is still in the primary stage, there are still work on employment and entrepreneurship education is not important, recognize the concept of dislocation, the quality of teachers is not high, the curriculum unreasonable, imperfect education system, theory and practice of light weight problems and shortcomings, the graduates comprehensive quality and practical ability is poor, it is difficult to adapt to the needs of the market and the economic and social development.

D. The influence of social psychology on College Students' employment concept

College Students' employment concept includes college students' career ideal, employment concept, employability and quality, employment psychology, career evaluation and self-evaluation, job hunting skills, etc.. At present, due to the Chinese ingrained social tradition, social status, heavy weight material benefits and stable work and heavy self employment concept, is still deeply affect my family and the college graduates employment concept. Many of the graduates tend to choose the more developed economic regions and big city employment, hope the government department and the administrative institutions such as stable operation, good prospects for the development of occupation, occupation career planning to rely too much on family background and the relatives and friends, "and rely on" serious thinking, lack of market competition and self seeking industry the idea, only talk about hobbies, interests and employment wages, but rarely talk about innovation, service and dedication, self interests as the center of the obvious tendency.

In short, lag, because the reform of higher education system and mechanism of talent supply structure and quantity and economic development gap, rapid changes in the demand for talent employment concept of labor market segmentation, multiple superposition and other complex reasons of graduates is to be changed, which led to and exacerbated the structural contradiction of employment of College graduates. In the implementation of market-oriented allocation of human resources under the background of the society, colleges and universities should take social and economic development of all kinds of professionals of the actual demand signal as the logical starting point, and constantly improve the autonomous universities and self restraint mechanism, and actively promote the professional setting and personnel training mode reform, strengthen innovation and entrepreneurship education efforts to deal with the employment psychological problems of graduates, constantly to improve the quality of students, in order to effectively alleviate the problem of the difficult employment of College graduates.

\section{Acknowledgements}

The Department of education of Jilin province " 13th Five-Year " ordinary program: analysis of College Students' employment psychology and negative peer support "education mode" (GH170074) is one of the results. 


\section{References}

[1] Chen Ying, Zhang Pengyu, Wang Guanshu. Study on the employment psychological characteristics and intervention of local applied undergraduate students [J]. ideological and political education research, 2015,31 (03): 138-140.

[2] Zhao Dinggui. College students' employment psychological problems, attribution and Strategies of [J]. second Chongqing Teachers College, 2015,28 (05): 110-112+130+176

$\mathrm{Wu}$ [3]. Analysis of the appearance and causes of College Students' employment psychology [J]. Journal of Hubei Correspondence University, 2016,29 (09): 17-18.

[4] Xu Yinan 's college graduates employment. How to cultivate the correct psychological [J]. of Higher Education Journal, 2016, (18): 219-220.

[5] Wang Jie Yu. College students' employment psychology and [D]. Strategy Research of Jilin Agricultural University, 2013.

[6] Cao Shaoping. Analysis and Countermeasures of College Students' employment psychological barriers in the new situation [J]. education and teaching forum, 2013, (05): 273-274. 